\title{
Educational needs in families of pediatric liver and kidney transplant recipients: A quality improvement project
}

\author{
Katelin daCruz ${ }^{1}$ (D) | Melissa K. Cousino ${ }^{1}$ (D) $\mid$ Tanya Smith $^{2}$ | Jacob Bilhartz ${ }^{1}$ | \\ Sally J. Eder ${ }^{1}$ | Emily M. Fredericks ${ }^{1}$
}

${ }^{1}$ Department of Pediatrics, University of Michigan, Ann Arbor, Michigan

${ }^{2}$ Department of Social Work, C.S. Mott Children's Hospital, Ann Arbor, Michigan

\section{Correspondence}

Emily M. Fredericks, Division of Pediatric Psychology, Department of Pediatrics, University of Michigan Medical School, C. S. Mott Children's Hospital, Ann Arbor, MI.

Email:emfred@med.umich.edu

Funding information

A Generous Donation to the University Of Michigan Transplant Center from Dr. Ida Malian

\begin{abstract}
Parents of pediatric liver and kidney transplant recipients were surveyed regarding their current education plans (eg, Individualized Education Program, 504), satisfaction with these plans, and interest in educational support from the psychosocial transplant team. Survey results indicate high rates of IEP and 504 plans, academic and related services, and accommodations among this population. The majority of parents/guardians reported satisfaction with their child's current school plan and did not report need for additional transplant team support specific to school services on the survey measure. However, other information highlights the importance for pediatric transplant teams to consider other ways to support this population's educational needs.
\end{abstract}

KEYWORDS

education, kidney, liver, psychosocial

\section{1 | INTRODUCTION}

As the number of children who achieve long-term survival following solid organ transplantation (SOT) increases, it is becoming increasingly important to understand and optimize their long-term functional outcomes. ${ }^{1,2}$ In pediatric populations, academic performance is a primary functional outcome as successful completion of primary and secondary education is crucial for independent functioning as an adult. As such, the American Academy of Pediatrics has a clear position that pediatric providers should address the educational needs of children with chronic illnesses as an integral part of care. ${ }^{3}$

Although the majority of pediatric liver ${ }^{4-7}$ and kidney transplant patients ${ }^{8-10}$ have been found to display cognitive functioning in the average to low average range (meaning IQ score typically in the mid-80s to low 90s), an increased prevalence of scores in the

Abbreviations: $A D H D$, attention deficit hyperactivity disorder; $\mathrm{Cl}$, cognitive impairment ; IEP, Individual Education Program; OHI, other health impairment; PDSA, Plan-Do-StudyAct; QI, quality improvement; SLD, specific learning disability; SOT, solid organ transplantation; SPLIT, studies of pediatric liver transplantation. borderline or impaired range is present among this population when compared to healthy controls. ${ }^{11-13}$ Transplantation may contribute to improvements in cognitive functioning for some; however, age of disease onset, illness severity and chronicity, responsiveness to pretransplant interventions, and premorbid cognitive functioning likely all play a role in post-transplant cognitive functioning. ${ }^{11,13}$ For the population as a whole, it appears that end-stage kidney and liver disease can result in long-term cognitive impairments that are not completely rectified by successful transplantation.

Several possible mechanisms for this decreased cognitive function have been hypothesized including the impact of illness and treatment on the developing brain and the impact of multiple hospitalizations on development and behavior. Many children with liver failure experience poor nutritional status prior to transplant, which has been associated with poorer neurodevelopmental outcomes. ${ }^{14}$ For individuals with chronic kidney disease, there are risks of neurological complications of uremia, cerebrovascular accidents due to ultrafiltration-related arterial hypotension, hypertensive encephalopathy, and intracranial hypertension. ${ }^{15}$ Youth with end-stage 
kidney and liver disease during infancy may be particularly vulnerable to cognitive delay because the onset of their illness occurs during a period of rapid and sensitive maturation. While transplantation addresses medical problems, it also exposes patients to potentially neurotoxic medications ${ }^{16}$ and common neurologic complications including seizures and encephalopathy. ${ }^{17}$

There is some preliminary evidence that kidney and liver transplant populations also demonstrate higher rates of attention and executive function difficulties (eg, impulsivity, working memory, and planning) than populations without this chronic illness. Research into the neuropsychological profile of children post-kidney transplantation shows lower performance on complex auditory attention and visual working memory tasks. ${ }^{8}$ Performance on continuous performance tasks used to directly assess attention and inhibitory control has been found to be significantly impaired among youth with chronic kidney disease. ${ }^{18,19}$ Longer duration of chronic kidney disease is associated with increased risk of poor performance on this measure of attention. ${ }^{20}$ Parents of children with chronic kidney disease rate their children as having more difficulties with working memory, planning, and organizing skills than do parents of children without chronic kidney disease. ${ }^{21}$ Although not the same methodology, research showing higher rates of ADHD diagnosis in renal transplant recipients $(22.5 \%)$ than healthy controls (7.5\%) also demonstrates functional impairment in renal transplant recipients. ${ }^{22}$

Likely due to varied and complex interactions of cognitive, executive function, and academic opportunity factors, the pediatric kidney and liver transplant populations appear to have academic deficits that persist after transplantation. Basic reading skills, reading comprehension, math calculation, and math problem-solving skills of pediatric liver transplant recipients have all been found to be significantly below normative data for standardized measures. ${ }^{23,24}$ Research into pre- and post-renal transplant academic achievement shows that mathematics and reading performance at one year post-transplantation remained significantly below that of healthy controls. ${ }^{12}$ Together, low academic performance in liver and kidney transplant populations and lack of significant improvements from pre- to post-renal transplant indicate that academic deficits remain after liver or kidney transplantation.

While this provides some information about academic potential, there is limited literature on how liver and kidney transplant recipients perform in the school setting. ${ }^{25}$ However, it does appear that this population demonstrates high levels of educational service needs and multiple risk factors for poor educational outcomes. National level data from 2012 to 2013 indicate that $12.9 \%$ of all students in the United States have special education support, with $4.3 \%$ of students in the United States receiving special education services because of a specific learning disability. ${ }^{26}$ In comparison, the multisite SPLIT (studies of pediatric liver transplantation) study of pediatric liver transplant population found that $33.9 \%$ of the sample reported special education services and that $17.4 \%$ had a learning disability. ${ }^{27}$ Students with solid organ transplants are significantly more likely to have been retained, with one study of kidney transplant recipients indicating that $60 \%$ of the sample had been retained. ${ }^{22}$ This higher level of grade retention is problematic, as there are widely demonstrated negative academic achievement and socio-emotional outcomes (ie, peer competence, problem behaviors, and attendance) for retention. Retention has also been found to be one of the most powerful predictors of high school dropout, with retained students 2 to 11 times more likely to drop out of high school than promoted students. ${ }^{28}$ Post-transplant hospitalizations, possible subsequent hospitalizations, and frequent follow-up care appointments may also require youth to miss significant amounts of school. The SPLIT consortium found that roughly $33 \%$ of parents reported their children with liver transplantation had missed $>2$ weeks of school and $11 \%$ missed $>6$ weeks. ${ }^{27}$ This may put transplant recipients at higher risk of poor educational outcomes, as students with higher absenteeism rates have lower scores on national standardized tests and are one of the three main indicators of school dropout. 29,30

\section{1 | Intended improvement}

As reviewed above, there are clear indications of high educational needs and risks of the pediatric transplant populations. ${ }^{22,27}$ Professional organizations have highlighted the importance of education as an outcome for pediatric patients and the importance of good communication and liaison between families, educators, and health professionals and of teacher understanding of a student's special health needs. ${ }^{3,31}$ This population appears to be at risk of low academic achievement and to have higher need for individualized instruction or educational accommodations. ${ }^{9,12,23,24,27}$ Despite this clear need, structured programs to support re-entry into the school system and long-term educational success are relatively rare for children with chronic illness. ${ }^{25}$ Successful educational intervention programs have been implemented among pediatric oncology populations, highlighting the value of such efforts. $^{32}$

Within our institution, we identified a gap in our services with respect to supporting families throughout the special education process. At the time of this study, our program did not employ a standardized method for assessing and documenting educational needs and services, nor a formalized school liaison program. The specific aims of the quality assurance/improvement (QI) project were to: (a) develop an educational needs assessment survey appropriate for use with pediatric solid organ transplant recipients, (b) use the educational needs assessment to determine the level of educational services and parent interest in educational supports within the pediatric transplant population, (c) use the educational needs assessment to ensure that transplant social workers and psychologists are consistently documenting educational needs and services and utilizing limited resources to intervene most effectively, and (d) provide the transplant teams with information necessary to inform clinical decision making regarding educational support in the transplant team. 
FIGURE 1 The plan-do-study-act cycle for educational needs and services

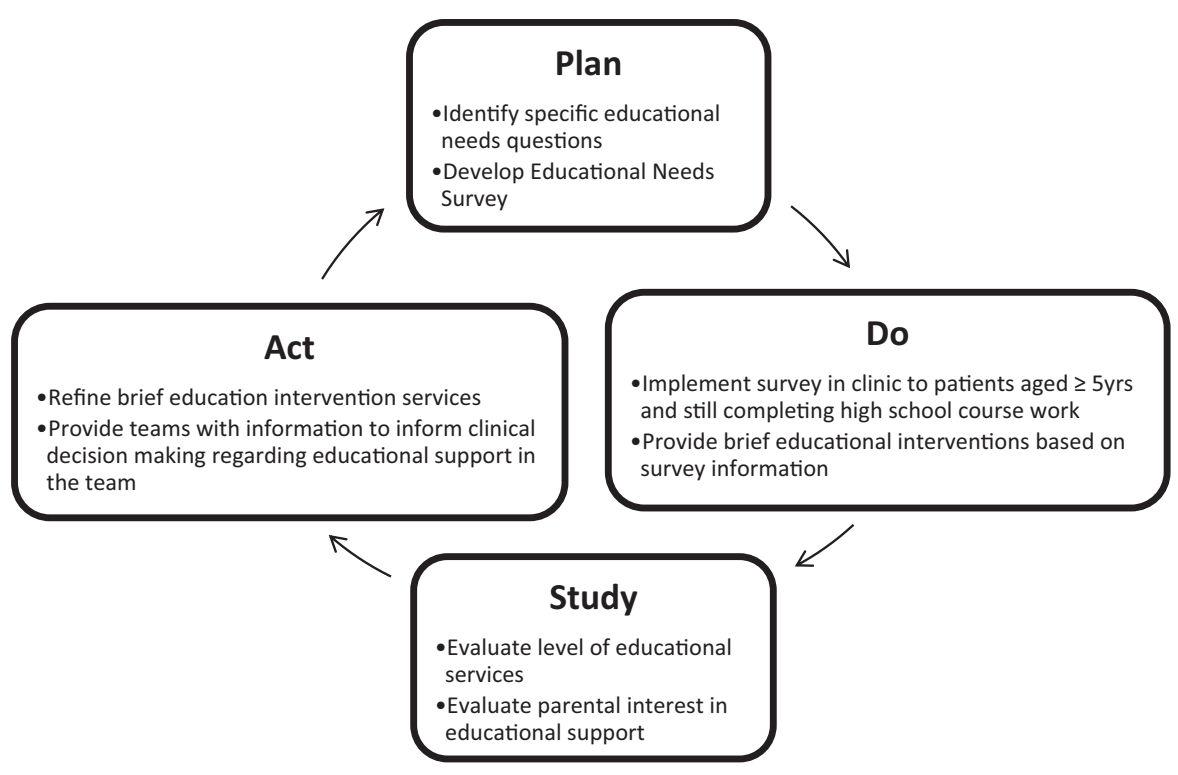

\section{2 | METHODS}

This quality improvement project was granted exemption by our Institutional Review Board. To improve the quality of educational assessment and intervention within the pediatric transplant clinic, a Plan-Do-Study-Act (PDSA) cycle methodology was utilized (Figure 1).

\section{1 | Plan}

A plan to implement a quality improvement study was developed by a multidisciplinary group of transplant providers across both the pediatric liver and kidney transplant programs. The educational needs assessment was developed by transplant psychology and reviewed by multidisciplinary transplant providers. This survey assesses service plans (Individual Education Program or IEP, 504 plan, Individualized Family Service Program), accommodations, intervention services, and parent satisfaction and interest in transplant team help related to these areas. The survey includes thirty-three total questions. Please see Supporting Information to review the survey.

\section{2 | Do}

Parent/guardians of school-aged patients within the pediatric liver and kidney transplant clinics completed the educational needs assessment once during the 8-month cycle of the quality improvement project as part of regular clinic visits. Families completed the survey if their child was between 5 years of age and 20 years of age and had not yet graduated high school. Surveys were administered by a member of the psychology or social work team via interview with the child and their parent(s). The level of child input varied based on their developmental level and knowledge of their own school services. The survey process took approximately 5 minutes.

Educational needs assessment results were reviewed by members of the multidisciplinary pediatric kidney and liver clinic teams.
Appropriate intervention was determined based on the parent responses to survey questions about their degree of satisfaction with current education plans, their desire for help from the transplant team, and if they were receiving services they had demonstrated need for, such as homebound services while restricted from school following transplantation. Resources and/or support services needed were identified and provided during the child's routine clinic visit. Sample interventions are outlined in Table 1. The intervention provided was documented in the child's medical record as part of standard clinical care.

\section{3 | Study}

All survey results were entered into a statistical software package for analysis. Descriptive statistics were computed to describe the educational needs and services among the study population. In addition, the clinic note of each patient with a completed parent survey was reviewed at the completion of the 8-month cycle to evaluate whether or not educational intervention was provided and documented.

\section{3 | RESULTS}

\section{1 | Participant demographics}

To achieve the aims of this QI project, the education needs assessment was developed and administered to 78 pediatric transplant patients (36 males, 42 females). The survey was administered to 55 pediatric liver transplant recipients and 23 pediatric kidney transplant recipients of school age between $11 / 8 / 2016$ and 5/2/2017. This represents $74.7 \%$ of the pediatric liver transplant patients and $39.4 \%$ of pediatric kidney transplant patients with clinic appointments during the study period within the targeted age-group. The majority of participants were white/Caucasian (59.5\%) and not Hispanic (97.4\%). Mean age was 12.05 years $(S D=3.86$, range: $5-18$ ), and the mean time since first transplant was 82 months (SD $=55$, range: $<1-198)$. Mean age at 


\begin{tabular}{|l|l|}
\hline Domain & Sample interventions \\
\hline Service plans (504, IEP) & $\begin{array}{c}\text { Parent education on education plans and parental } \\
\text { rights sample letter for requesting an evaluation for } \\
\text { eligibility }\end{array}$ \\
\hline Homebound & $\begin{array}{l}\text { Explanation of homebound and school legal } \\
\text { obligations; Contacted school staff to facilitate } \\
\text { homebound services }\end{array}$ \\
\hline Self-contained classroom & $\begin{array}{l}\text { Informal assessment of appropriateness of } \\
\text { placement }\end{array}$ \\
\hline Academic tutoring & $\begin{array}{l}\text { Sample letter for requesting meeting of the special } \\
\text { education team to review progress and current }\end{array}$ \\
\hline Speech and occupational therapy & services \\
\hline Extra time for tests/ assignments & Sample letter for requesting an evaluation \\
\hline Medical accommodations & education team to review current accommodations \\
\hline
\end{tabular}

TABLE 1 Sample brief, clinic-based interventions for addressing educational needs transplant was 5.82 years (SD $=4.65$, range: 2 months- 17 years). The majority of liver transplant patients had a clinical diagnosis of Biliary Atresia, while diagnoses of kidney transplant patients were more varied. Table 2 provides detailed demographic information. The pediatric liver and kidney transplant groups did not differ significantly on the following demographic variables: age $(P=0.107)$, time since transplant $(P=0.762)$, or age at transplant $(P=0.077)$, gender $(P=0.305)$ or reported race $(P=0.492)$ or ethnicity $(P=0.582)$. The pediatric liver and kidney transplant patient groups did not differ significantly on frequency of IEP or 504 plans, special education eligibility category, Early On services, or any of the assessed accommodations $(P>0.05)$.

\section{2 | Educational services}

The majority of transplant patients surveyed had a current or previous IEP, ranging from $39.1 \%$ currently for kidney transplant patients to $61.8 \%$ ever for liver transplant patients. Of these patients with a current or past IEP, the majority qualified through an other health impairment $(\mathrm{OHI})$ eligibility category (34.1\%). However, 67\% of those who reported a special education eligibility category were eligible for a reason other than a health impairment. The next most frequent categories endorsed were specific learning disability (SLD) and cognitive impairment $(\mathrm{Cl})$. When provided with the list of options, the majority of parents were able to identify the eligibility category under which their child qualified for special education services. The number of patients with a current or past 504 plan ranged from $18.2 \%$ to $39.1 \%$.

Around one-quarter of patients surveyed received additional math or reading tutoring currently and had ever received occupational or speech therapy. Roughly $40 \%$ received accommodations of extra time on tests or for completing assignments. The majority, but not all, reported receiving the medical accommodations of excused absences and unlimited access to water, bathrooms, and hand washing or sanitizer. Of these patients, $14.7 \%(N=11)$ had been retained at least once. The majority of these were liver transplant patients $(\mathrm{N}=9)$. See Tables 3 and 4 for more information.

\subsection{Educational needs and transplant team intervention}

The majority of families (85\%) reported satisfaction with their child's service plans and only $16.6 \%$ expressed interest in help from the

\begin{tabular}{|c|c|c|c|}
\hline Liver & $\mathrm{N}$ (Percent) & Kidney & $\mathrm{N}$ (Percent) \\
\hline Biliary atresia & 31 (55.4\%) & Obstructive uropathy & $6(25 \%)$ \\
\hline Acute liver failure & $3(5.4 \%)$ & Nephronophthisis & $3(12.5 \%)$ \\
\hline Hepatoblastoma & $3(5.4 \%)$ & Renal dysplasia & 2 (8.3\%) \\
\hline $\begin{array}{l}\text { Genetic conditions (maple } \\
\text { syrup urine disease, Alagille } \\
\text { syndrome, OTC deficiency) }\end{array}$ & 8 (14.3\%) & $\begin{array}{l}\text { Genetic conditions (Alport } \\
\text { syndrome, Eagle-Barrett } \\
\text { syndrome) }\end{array}$ & 4 (16.7\%) \\
\hline $\begin{array}{l}\text { Other cholestatic conditions } \\
\text { (PFIC, neonatal cholestatic } \\
\text { liver disease) }\end{array}$ & $5(8.9 \%)$ & $\begin{array}{l}\text { Nephrotic syndrome (focal } \\
\text { segmental glomerulosclero- } \\
\text { sis, glomerulonephritis) }\end{array}$ & 2 (8.3\%) \\
\hline \multirow[t]{2}{*}{ Other } & $6(10.7 \%)$ & Cortical necrosis & $3(12.5 \%)$ \\
\hline & & Other & 4 (16.7\%) \\
\hline
\end{tabular}

TABLE 2 Diagnosis of transplant patients 
TAB LE 3 Frequency of special education eligibility categories

\begin{tabular}{|c|c|c|c|}
\hline & $\mathrm{N}$ & $\%$ of IEP & $\%$ of sample \\
\hline $\begin{array}{l}\text { Other health impairment } \\
(\mathrm{OHI})\end{array}$ & 15 & 34.1 & 19.2 \\
\hline OHI-ADHD & 4 & 9.1 & 5.1 \\
\hline $\begin{array}{l}\text { Specific learning disability } \\
\text { (SLD) }\end{array}$ & 7 & 15.9 & 9 \\
\hline Cognitive impairment (CI) & 5 & 11.4 & 6.4 \\
\hline $\begin{array}{l}\text { Speech and language } \\
\text { impairment }\end{array}$ & 2 & 4.5 & 2.6 \\
\hline Autism spectrum disorder & 3 & 6.8 & 3.8 \\
\hline Emotional impairment & 0 & - & - \\
\hline Other & 2 & 4.5 & 2.6 \\
\hline Don't know & 10 & 27.3 & - \\
\hline
\end{tabular}

Other eligibilities include multiple impairment, early childhood developmental delay

transplant team related to educational plans. However, brief intervention related to educational services was documented in the session containing the educational needs assessment for $30 \%$ of participants surveyed. The majority of this was providing parent education (18.7\%), followed by a sample letter or other documentation (7.5\%), and contacting the school or family (3.8\%). Of those who reported interest in team help with school service plans, 33\% did not receive any intervention that was documented by the psychosocial support members of the transplant team.

\section{4 | DISCUSSION}

This quality improvement study aimed to develop and administer a tool to determine the educational needs of pediatric transplant patients and to inform the delivery of education-focused interventions. Results indicate that this post-transplant population has a high level of educational needs. The majority of patients surveyed in the pediatric kidney and liver transplant clinics reported either special education services or a 504 general education accommodation plan. Participants in the sample had rates of special education plans six times higher than state and nationwide rates. ${ }^{33}$ In addition, parents/ guardians reported that their children received both medical and academic accommodations at school.

It may be expected that a population with a chronic illness would have higher rates of special education utilization. Indeed, the proportion of participants with an IEP who reported they received these services under an other health impairment eligibility (34.1\%) is more than double the nationwide proportion (14.4\%). In addition, while $19.2 \%$ of the sample reported special education services through an other health impairment eligibility, only around $1 \%$ of the nationwide population has special education services through this eligibility. This indicates that this high rate of special education services may in part be explained by school districts determining that a solid organ transplant and resulting complications result in "having limited strength, vitality, or alertness, including a heightened alertness to environmental stimuli, that results in limited alertness with respect
TAB LE 4 Frequency of special and general education service plans, services, and accommodations

\begin{tabular}{|c|c|c|c|c|c|c|}
\hline & \multicolumn{2}{|c|}{ Liver transplant } & \multicolumn{2}{|c|}{ Kidney transplant } & \multicolumn{2}{|c|}{ All transplant } \\
\hline & Current & Ever & Current & Ever & Current & Ever \\
\hline IEP & $33(60)$ & 34 (61.8) & $9(39.1)$ & $10(43.5)$ & $42(53.8)$ & $44(56.4)$ \\
\hline 504 Plan & $11(18.2)$ & $14(25.5)$ & $8(34.8)$ & $9(39.1)$ & $19(24.4)$ & $23(29.5)$ \\
\hline Early On & - & $20(36.4)$ & - & $4(17.4)$ & - & $24(30.8)$ \\
\hline Homebound & $8(14.5)$ & $17(30.9)$ & $2(8.7)$ & $7(30.4)$ & $10(12.8)$ & $24(30.8)$ \\
\hline Self-contained & $13(23.6)$ & $14(25.5)$ & $1(4.3)$ & $1(4.3)$ & $14(17.9)$ & 15 (19.2) \\
\hline Math tutoring & $15(27.3)$ & $16(29.1)$ & $6(26.1)$ & $7(30.4)$ & $21(26.9)$ & $23(29.5)$ \\
\hline Reading tutoring & $13(23.6)$ & $18(32.7)$ & $6(26.1)$ & $8(34.8)$ & $19(24.4)$ & 27 (34.6) \\
\hline $\begin{array}{l}\text { Occupational } \\
\text { therapy }\end{array}$ & $9(16.4)$ & 15 (27.3) & $3(13)$ & $7(30.4)$ & $12(15.4)$ & $22(28.2)$ \\
\hline Speech therapy & $14(25.5)$ & 23 (41.8) & $5(21.7)$ & 9 (39.1) & $19(24.4)$ & $21(26.9)$ \\
\hline Extra time-tests & $24(43.6)$ & $27(49.1)$ & $7(30.4)$ & 9 (39.1) & 31 (39.7) & $33(42.3)$ \\
\hline $\begin{array}{l}\text { Extra } \\
\text { time-assign- } \\
\text { ments }\end{array}$ & $20(36.4)$ & $22(40)$ & $\begin{array}{l}10 \\
(43.5)\end{array}$ & $10(43.5)$ & $30(38.5)$ & $32(41)$ \\
\hline $\begin{array}{l}\text { Excused } \\
\text { absences }\end{array}$ & 37 (67.3) & $38(69.1)$ & $\begin{array}{l}18 \\
(78.3)\end{array}$ & $18(78.3)$ & $55(70.5)$ & $56(71.8)$ \\
\hline Water & 39 (70.9) & $40(72.7)$ & $20(87)$ & $20(87)$ & $59(75.6)$ & $60(76.9)$ \\
\hline Bathroom & $33(60)$ & 35 (63.6) & $\begin{array}{c}19 \\
(82.6)\end{array}$ & $19(82.6)$ & $52(66.7)$ & $54(69.2)$ \\
\hline $\begin{array}{l}\text { Wash hands/ } \\
\text { sanitizer }\end{array}$ & 38 (69.1) & 39 (70.9) & $20(87)$ & $20(87)$ & $58(74.4)$ & $59(75.6)$ \\
\hline
\end{tabular}

$\mathrm{N}$ (percentage of sample). 
to the educational environment, that- (a) is due to chronic or acute health problems and (b) adversely affects a child's educational performance." ${ }^{34}$ However, it is also important to note that the rates of specific learning disability, speech and language impairment, and cognitive impairment in the sample as a whole are also roughly twice as high as that of the US population. ${ }^{32}$ In addition, $67 \%$ of those with an IEP were eligible for a reason outside of their liver or kidney illness. Therefore, this population may be at higher risk of difficulties in other areas that affect academic outcomes in addition to increased risk due to their medical illness.

While survey results indicate that the majority of parents/ guardians were satisfied with their child's current school services and were not requesting additional transplant team support, it was clinically observed that there is need for more support than indicated. For example, less than a quarter of surveyed parents reported need for additional transplant team support specific to school services on the survey measure. However, sometimes the family and transplant social worker or psychologist would identify an area of need together following the survey during clinical interview. In addition, despite the high prevalence of IEPs, nearly $1 / 3$ of parents/guardians did not know their child's special education classification. Together, this suggests that parents may report satisfaction because of a limited understanding of special education processes and services and not because their child's educational needs are being met appropriately.

\subsection{Limitations and future directions}

This study was limited by its reliance on self-report and lack of objective academic achievement data to confirm educational needs. Because of this, it is difficult to determine the exact cause and meaning of high levels of special education services in this population. Rates of special and general education plans in this pediatric liver transplant group were significantly higher in this sample compared to a large study reporting special education rates in a pediatric liver transplant population. Studies conducted by the SPLIT consortium reported a special education prevalence of $33.9 \%$ compared to $56.4 \%$ in the current study. ${ }^{27}$ Because both studies are based on parent report information, it is difficult to rule out variance in parent report as a reason for this difference. Similarly, we did not obtain specific details regarding grade retention, and thus, we are unable to speculate as to why these children have higher than expected rates of retention. Obtaining collateral information regarding academic functioning, including grade retention, is an area of focus for both future research and clinical practice.

Although not statistically significant, the rates of both plans were lower in the kidney transplant population than in the liver transplant population. It should be noted that between-group differences could be a reflection of unequal numbers of kidney and liver transplant recipients included in this study. However, these data may suggest that the liver transplant population has a higher frequency of need for accommodations or individualized instruction. An alternative explanation supported by differences between kidney and liver recipients and lower levels in the large multisite SPLIT study is that rates of school service plans differ based on level of psychosocial support in the chronic illness clinic. At the time of our needs assessment, pediatric psychology had been embedded in the liver transplant program for many years, while the pediatric psychology services in kidney transplant were newly implemented. Thus, embedded pediatric psychology support may result in earlier identification of educational needs and referral for appropriate services. Similarly, in a multisite study like SPLIT, there is likely variation in the level of psychosocial support, which may account for differences between study findings and this national dataset. However, no conclusions on which explanation is more likely can be made without the ability to directly analyze educational needs and services by reviewing special education plans and directly assessing academic achievement.

In addition, it is difficult to understand the meaning of high levels of IEPs, 504 plans, and specific services and accommodations. This may indicate schools in the state are generally recognizing the needs of this population. It may also reflect the success of the pediatric transplant teams in supporting families in accessing appropriate education supports. It is also possible, however, that even more participants have educational impairment requiring special education services or accommodations. Unfortunately, this remains an empirical question that cannot be answered with the existing data as no direct, standardized cognitive or academic achievement data were collected and there was no evaluation of other factors or diagnoses that might impact educational performance.

Future research into the educational needs of this population should include direct assessment of academic and cognitive functioning, speech and language skills, and mental health in addition to collection of any current IEPs or 504 plans. In addition, with larger sample sizes, it would be beneficial to identify health status factors in order to examine their relation to educational needs.

\subsection{Implications for clinical practice}

It is clear from this study that there are areas for improvement in psychosocial support of families served by this and other pediatric transplant clinics. For example, despite the support of nurse coordinators and the psychosocial team members, $24 \%-30 \%$ of parents of pediatric transplant recipients report that their child is not receiving recommended medical accommodations at school, which were unlimited ability to wash hands or use hand sanitizer during the school day and unlimited bathroom use. Lastly, multiple aspects of the data and observations from the implementation of the survey indicate that parents have limited understanding of special education processes and their parental rights. Indeed, about one-quarter of parents were unable to identify their child's special education eligibility even when provided a list of options. Psychosocial team members identified and addressed educational needs in $30 \%$ of encounters, despite the fact that parents reported interest in support in about $18 \%$ of encounters. In addition, this survey needed to be administered as an interview because when trialed as a paper and pencil 
survey, parents required many explanations and alternative terms for different services and accommodations.

Supporting the educational needs of pediatric transplant recipients places significant demands on school personnel, which they may not feel prepared to meet without significant support from a medical team. As shown by the high rates in this sample, school staff will likely be involved in developing an individualized educational plan. Other significant responsibilities of school staff can include implementing and documenting accommodations, coordination of homebound educational services, developing systems for monitoring health at school, collaborating with the child's medical team, and possible involvement in medication administration. ${ }^{25}$ When surveyed, teachers and other school staff report concerns about when and how the school will be informed of health needs and how personnel will be taught about health needs including medication effects and infection risks. ${ }^{35}$ Parents of children with chronic illness report concerns about peer teasing, physical wellbeing, and when and how the reintegration process will occur. ${ }^{35}$ Any school re-entry plan will therefore be more successful when the medical team includes staff able to address these school and parent concerns.

In the next phase of this quality improvement project, the psychosocial transplant team members will be developing different strategies to support the educational needs of this population. For example, it may be appropriate to have a designated education liaison, similar to a hospital teacher or education fellow seen in other types of chronic illness clinics. The presence of this role would allow for more frequent assessment and intervention in the area of educational outcomes, such as repeated calls to coordinate services with school personnel. The psychosocial transplant team will also be exploring collaboration with education experts to create a system for educating parents on their rights related to special education and available educational services.

\section{ACKNOWLEDGMENTS}

This project was partially funded through a Generous Donation To The University Of Michigan Transplant Center from Dr. Ida Malian.

\section{AUTHORS CONTRIBUTIONS}

All authors: made substantial contributions to the conception and design of the quality improvement project, acquisition of data, and/ or analysis and interpretation of data; provided critical feedback on the study tools and/or manuscript drafts and approval of the final manuscript.

\section{ORCID}

Katelin daCruz (D) https://orcid.org/0000-0002-0240-2340

Melissa K. Cousino (iD https://orcid.org/0000-0002-0041-0830

Emily M. Fredericks (D) https://orcid.org/0000-0002-3110-4983

\section{REFERENCES}

1. Ojo AO, Hanson JA, Wolfe RA, Leichtman AB, Agodoa LY, Port FK. Long-term survival in renal transplant recipients with graft function. Kidney Int. 2000;57(1):307-313.

2. Wallot M. Long-term survival and late graft loss in pediatric liver transplant recipients-a 15-year single-center experience. Liver Transpl. 2002;8(7):615-622.

3. American Academy of Pediatrics Council on Children With Disabilities, Cartwright JD. Provision of educationally related services for children and adolescents with chronic diseases and disabling conditions. Pediatrics. 2007;119(6):1218-1223.

4. Kaller T, Langguth N, Petermann F, Ganschow R, Nashan B, Schulz $\mathrm{KH}$. Cognitive performance in pediatric liver transplant recipients. Am J Transplant. 2013;13(11):2956-2965.

5. Kaller T, Boeck A, Sander K, et al. Cognitive abilities, behaviour and quality of life in children after liver transplantation. Pediatr Transplant. 2010;14(4):496-503.

6. Schulz KH, Wein C, Boeck A, Rogiers X, Burdelski M. Cognitive performance of children who have undergone liver transplantation. Transplantation. 2003;75(8):1236-1240.

7. Mohammad S, Sorensen LG, Alonso EM. Psychosocial, cognitive, and quality of life considerations in the child with liver disease and their family. In: Murray KF, Horslen S, eds. Diseases of the liver in children: evaluation and management. New York, NY; Springer, New York; 2014:133-150.

8. Haavisto A, Korkman M, Holmberg C, Jalanko H, Qvist E. Neuropsychological profile of children with kidney transplants. Nephrol Dial Transplant. 2012;27(6):2594-2601.

9. Brouhard BH, Donaldson LA, Lawry KW, et al. Cognitive functioning in children on dialysis and post-transplantation. Pediatr Transplant. 2000;4(4):261-267.

10. Duquette PJ, Hooper SR, Wetherington CE, Icard PF, Gipson DS. Brief report: intellectual and academic functioning in pediatric chronic kidney disease. J Pediatr Psychol. 2007;32(8): 1011-1017.

11. Moser JJ, Veale PM, McAllister DL, Archer DP. A systematic review and quantitative analysis of neurocognitive outcomes in children with four chronic illnesses. Pediatr Anesth. 2013;23(11):1084-1096.

12. Fennell RS, Rasbury WC, Fennell EB, Morris MK. Effects of kidney transplantation on cognitive performance in a pediatric population. Pediatrics. 1984;74(2):273-278.

13. Gerson AC, Butler R, Moxey-Mims M, et al. Neurocognitive outcomes in children with chronic kidney disease: current findings and contemporary endeavors. Ment Retard Dev Disabil Res Rev. 2006;12(3):208-215

14. Nyaradi A, Li J, Hickling S, Foster J, Oddy WH. The role of nutrition in children's neurocognitive development, from pregnancy through childhood. Front Hum Neurosci. 2013;7:97.

15. Brouns R, De Deyn PP. Neurological complications in renal failure: a review. Clin Neurol Neurosurg. 2004;107(1):1-16.

16. Wijdicks E. Neurotoxicity of immunosuppressive drugs. Liver Transpl. 2001;7(11):937-942.

17. Živković SA. Neurologic complications after liver transplantation. World J Hepatol. 2013;5(8):409.

18. Hartung EA, Kim JY, Laney N, et al. Evaluation of neurocognition in youth with ckd using a novel computerized neurocognitive battery. Clin J Am Soc Nephrol. 2016;11(1):39-46.

19. Fennell RS, Fennell EB, Carter RL, Mings EL, Klausner AB, Hurst JR. A longitudinal study of the cognitive function of children with renal failure. Pediatr Nephrol. 1990;4(1):11-15.

20. Mendley SR, Matheson M, Shinnar S, et al. Duration of chronic kidney disease reduces attention and executive function in pediatric patients. Kidney Int. 2015;87(4):800-806. 
21. Hooper SR, Laney N, Radcliffe J, et al. Executive functioning in children, adolescents, and young adults with chronic kidney disease. $J$ Dev Behav Pediatr. 2015;36(9):734-742.

22. Berney-Martinet S, Key F, Bell L, Lépine S, Clermont M-J, Fombonne E. Psychological profile of adolescents with a kidney transplant. Pediatr Transplant. 2009;13(6):701-710.

23. Kennard BD, Stewart SM, Phelan-McAuliffe D, et al. Academic outcome in long-term survivors of pediatric liver transplantation. $J$ Dev Behav Pediatr. 1999;20(1):17-23.

24. Sorensen LG, Neighbors K, Martz K, Zelko F, Bucuvalas JC, Alonso EM. Cognitive and academic outcomes after pediatric liver transplantation: functional outcomes group (FOG) results. Am J Transplant. 2011;11(2):303-311.

25. Kliebenstein MA, Broome ME. School re-entry for the child with chronic illness: parent and school personnel perceptions. Pediatr Nurs. 2000;26(6):579-582.

26. Snyder TD, Brey CD, Dillow SA. Digest of Education Statistics 2015. Washington, D.C.: National Center for Education Statistics; 2016.

27. Gilmour SM, Sorensen LG, Anand R, Yin W, Alonso EM. School outcomes in children registered in the studies for pediatric liver transplant (SPLIT) consortium. Liver Transpl. 2010;16(9):1041-1048.

28. Jimerson SR, Anderson GE, Whipple AD. Winning the battle and losing the war: examining the relation between grade retention and dropping out of high school. Psychol Sch. 2002;39(4):441-457.

29. Mac Iver MA, Mac Iver DJ Beyond the Indicators: An Integrated School-Level Approach to Dropout Prevention. Arlington, VA: George Washington University Center for Equity and Excellence in Education; 2009.

30. Ginsberg A, Jordan P, Chang H. Absences add up: how school attendance influences student success. Attendance Works. 2014.
31. Harris K, Farrell P. Educating children and young people with medical needs: effective provision and practice. Support Learn. 2004;19(1):13-18.

32. Thompson AL, Christiansen HL, Elam M, et al. Academic continuity and school reentry support as a standard of care in pediatric oncology. Pediatr Blood Cancer. 2015;62(8):S805-S817.

33. Office of Special Education and Rehabilitation Services. 38th Annual Report to Congress on the Implementation of the Individuals with Disabilities Education Act, 2016. Arlington, VA: U.S. Department of Education; 2016.

34. Individuals with Disabilities Education Act, §20 U.S.C. 1412 (2004).

35. Annunziato RA, Jerson B, Seidel J, Glenwick DS. The psychosocial challenges of solid organ transplant recipients during childhood. Pediatr Transplant. 2012;16(7):803-811.

\section{SUPPORTING INFORMATION}

Additional supporting information may be found online in the Supporting Information section at the end of the article.

How to cite this article: daCruz K, Cousino MK, Smith T, Bilhartz J, Eder SJ, Fredericks EM. Educational needs in families of pediatric liver and kidney transplant recipients: A quality improvement project. Pediatr Transplant.

2019;23:e13412. https://doi.org/10.1111/petr.13412 